\title{
Patriarcado y políticas de género y trabajo: desafíos teóricos y metodológicos*
}

\section{Heidi Tinsman**}

Realmente es un gran honor estar aquí y poder compartir mi trabajo con ustedes. Gracias a todos ustedes por estar aquí esta tarde. Agradezco al Instituto Interdisciplinario de Estudios de Género y al Grupo de Investigación Histórica Familias e Infancias, a la Facultad, a la Universidad de Buenos Aires y al Proyecto de la Agencia Nacional de Promoción Científica y Tecnológica. Yo sé que se necesitan trabajo y recursos para recibir una visita y estoy muy agradecida a todos ellos y ellas que lo hicieron posible. Por muchos años he deseado tener un lazo académico con la comunidad feminista argentina. En verdad fue un truco del destino que me enfocara al final en la historia de Chile, porque algunos de los primeros trabajos intelectuales que leí, que me inspiraron para enfocarme en la historia de género, fueron escritos por argentinas o extranjeras trabajando historia argentina como Dora (Barrancos), Marisa Navarro, Elizabeth Jelin. Uno de los directores de mi tesis doctoral era Daniel James, que en esa época trabajaba la historia de la mujer en el peronismo. Entonces para mí es realmente lindo estar, por fin, en Argentina. Voy a leer hoy porque creo que voy a expresarme más claro. Ojalá no se aburran por eso.

"Patriarcado" es una palabra bastante seria y como concepto analítico va y viene de moda. Pero, en mi opinión, siempre es relevante para pensar en la política de las relaciones de género y sexualidad como formas de poder. Lamentablemente, hoy en día, con la franca actitud misógina de "mi presidente" Donald Trump y un Congreso que pretende quitar a la mujer sus derechos reproductivos, vemos que "el patriarcado" no está fuera de moda políticamente. Y no debe estarlo analíticamente tampoco.

Por supuesto, lo que significa "patriarcado" ha cambiado mucho con las décadas de debates feministas y queer. Si en los setenta se tomaba "patriarcado" como "un sistema/estructura unitaria" del control de la mujer por el hombre, ahora se lo plantea más como una constelación heterogénea de distintas formaciones del poder. Reconocemos que no todos los hombres se benefician del patriarcado, o no de la misma manera. Y que las relaciones patriarcales producen jerarquías entre los hombres igual que entre las mujeres, articuladas por clase, raza, generación, etcétera.

El concepto de "patriarcado" juega un rol central en mi trabajo como historiadora de los movimientos campesinos y de la política agraria en Chile, y más recientemente en mi interés en la historia transnacional y culturas del consumo. Esto tiene mucho que ver con mi viaje intelectual como norteamericana trabajando en Sudamérica. Yo llegué a Chile por primera vez como estudiante de posgrado en 1991, un año después
* Edición de Agostina Gentili, Karin Grammático y Carolina Perelló.

** Profesora de la Universidad de California Irvine, estuvo en Buenos Aires en el invierno de 2017. Dio una conferencia en la que discutió a fondo cómo pensar y usar la noción de patriarcado, crucial en su enfoque de trabajo. La actividad estuvo organizada por el Grupo de Investigación Histórica Familias e Infancias del Instituto de Estudios de Género de la Facultad de Filosofía y Letras de la Universidad de Buenos Aires, contó con el apoyo del proyecto "Familias, infancias y jerarquías sociales" de la Agencia Nacional de Promoción Científica y Tecnológica y de la propia Facultad. La Caja Feminista está dedicada en exclusiva a esta original dedicada en exclusiva a esta original
y lúcida historiadora que obtuvo su doctorado en Princeton y escribió libros y artículos de gran relevancia para comprender la historia de los trabajadores, de América Latina y la historia trasnacional. 
de que cayó Pinochet. Venía de un clima intelectual entonces muy marcado por debates sobre las ideas de Joan Scott y su libro Género y la política de historia (2012), donde planteó que fue importante estudiar el "género" como una relación de poder, socialmente construida: tanto lo masculino como lo femenino eran construcciones históricas. Según Scott, la tarea de la historiadora no es simplemente "buscar el rol de la mujer," sino examinar el proceso de formación de las ideas sobre la masculinidad y la feminidad, y cómo construían una relación de poder en sí misma. Además, Scott proponía que el género marcaba a todas las relaciones sociales y políticas. Siguiendo a Foucault, dijo que constituía un discurso o tecnología del poder a todo nivel. (En verdad, el libro de Scott fue una síntesis de las ideas y los debates de muchísimas feministas, no solamente de ella, y ni siquiera de los EE.UU. Ella misma siempre dijo esto; a quien cito como una taquigrafía.)

En los EE.UU. de los noventa, la historia de la mujer ya llevaba veinte años, producto de los movimientos feministas y de derechos civiles de los sesenta. Pero el concepto de género como una "tecnología del poder" ofreció algo distinto: planteaba la importancia de estudiar el género no solo donde obviamente apareciera "la mujer" o "la mujer en relación con el hombre," sino en todas las instituciones, en todos los movimientos sociales, en todas las formaciones culturales y sistemas simbólicos. Pero Scott no habló del "patriarcado". Al contrario, su concepto de género como un modo de poder multidimensional rechazó la utilidad de pensar en términos de "patriarcado", lo cual se asociaba en este momento con una "estructura" o "sistema".

En Chile, el ambiente intelectual de los ochenta y noventa era diferente. Se hablaba mucho del "patriarcado" pero afuera de la universidad, no adentro. La "historia de la mujer" se hacía en las calles y en las ONG feministas, escrita por académicas activistas y dirigentes intelectuales de los movimientos de mujeres contra Pinochet. Ellas planteaban el tema de género en términos de la inclusión igualitaria de la mujer en la reconstrucción de la democracia. La tarea de rescatar y representar la presencia de la mujer dentro de la historia nacional era parte del proyecto urgente de reconquistar derechos civiles y construir la ciudadanía en forma igualitaria.

Se utilizaba el concepto de "patriarcado" para enfocar en el poder estatal. Criticaban la dictadura como un patriarcado brutal y lanzaron campañas contra la violencia doméstica que comparaba los golpes contra la mujer con el golpe de Estado y las violaciones de los derechos humanos. Como señaló la infatigable intelectual Julieta Kirkwood (1986), el lema feminista "Democracia en el país y en la casa" planteaba al patriarcado como un problema político a nivel nacional tanto como familiar y personal. Kirkwood insistía en que las relaciones patriarcales dentro de la vida política eran más antiguas que la dictadura y no iban a desaparecer con Pinochet: formaban las relaciones de partidos políticos de centroizquierda, del trabajo, del movimiento por la democracia y dentro de la universidad y del debate cívico. Ella destacó la tarea de luchar/negociar contra el/los patriarcado(s) en muchos espacios diferentes y la importancia de las organizaciones y metodologías feministas independientes. Igual que Scott, el trabajo de Kirkwood refleja debates de muchas feministas latinoamericanas, no solo de ella y ni siquiera de las chilenas como Ximena Aranda, Ximena

1. Aranda, X. (1981). Mujer, familia, y Santiago de Chile: Ford Foundation: Valdés, X. (1992). Mujer, trabajo, y medio ambiente: los nudos de la y medio ambiente: los nudos de la
modernización agraria. Santiago de Chile: CEM; Valdés, T. (1992). Ser mujer en sectores populares urbanos. Santiago de Chile: FLACSO; y Gaviola, E., Jiles Moreno, X., Lopresti Martínez, L., Rojas Mira, C. (1986). Queremos votar en las próximas elecciones: historia del movimiento femenino chileno, 1913-1952, Santiago de Chile: CEM.
Valdés, Teresa Valdés, etcétera.

Pero a mí me llamó mucho la atención cómo Kirkwood, de hecho, planteaba el problema del patriarcado como "múltiples terrenos políticos": varios sitios de negociación y lucha. Para mí, este tenía mucho en común con el concepto de "género" elaborado por Joan Scott, aunque a Scott no le gustara la palabra "patriarcado". Además, "patriarcado" como "terreno de lucha política" tenía mucho en común con los debates latinoamericanistas en este momento sobre Gramsci y la "hegemonía": el concepto de dominación política como algo basado en la producción del consentimiento y 
el sentido común, lo que parezca "natural". En los estudios latinoamericanos del Atlántico Norte en esta época, el debate sobre la hegemonía era enorme, influido tanto por las ideas de Ernesto Laclau aquí en Argentina, como por el trabajo de Raymond Williams y los estudios culturales marxistas de Gran Bretaña, la antropología cultural de Clifford Geertz y William Roseberry en EE.UU. Pero notemos que ninguno de estos grandes revisionistas del marxismo tenía mucho que decir sobre el género o el patriarcado como una forma de hegemonía: tal vez la forma de dominación política más normalizada.

Este era un trabajo para nosotras, las feministas. Y había muchas de nosotras y nosotros que comenzábamos a trabajar el concepto de patriarcado como una hegemonía dinámica que se negocia. Una influencia muy importante en este giro fue la filósofa australiana Carole Pateman y su libro El contrato sexual (1995), en el que plantea que la subordinación sexual de la mujer al hombre fue la base del contrato social imaginado por la Ilustración: el individuo-ciudadano que se entiende como un hombre con soberanía sobre una familia y una mujer. Esto fue importante para mí y para otras colegas al trabajar relaciones conyugales como pactos patriarcales: acuerdos sobre "deberes y derechos" dentro del matrimonio o la familia que se construyen y se pelean. Finalmente, Pateman fue importante para mí como historiadora del trabajo porque ella escribía dentro de la tradición marxista-feminista que plantea al capitalismo y al patriarcado como modos de poder que se articulan mutuamente. Insiste en que el género y la sexualidad como relaciones del poder están construidos por -y construyen- divisiones de labor. En fin, que no es posible hacer historia de género/ sexualidad sin hacer historia laboral. (Marx mismo dijo que la primera división laboral fue el poder del hombre sobre la mujer.)

Para mí, la mejor manera de elaborar estas ideas es compartir mis investigaciones concretas. Así que presentaré algunos argumentos y conceptos de dos libros que también son ejemplos de la evolución de mi trabajo.

El libro La tierra para el que la trabaja (2009) es una historia de género y sexualidad durante la reforma agraria chilena, no solamente la de Salvador Allende sino también la del gobierno demócrata cristiano de Eduardo Frei Montalva en los años sesenta, que -yo insisto- fue mucho más radical de lo que antes se apreciaba. Con respeto a las relaciones de género, sostengo tres argumentos principales: primero, digo que las mujeres campesinas no fueron excluidas de la reforma agraria, como planteaban las primeras críticas feministas. Digo que no fueron excluidas, aunque fueron los hombres quienes recibieron los títulos de la tierra redistribuida y los hombres fueron el noventa y cinco por ciento de los miembros de los sindicatos y Centros de Reforma Agraria. Sin embargo, muestro que la mujer campesina jugaba un rol importante dentro de los Centros de Madres, los Comités de abastecimiento popular y la toma de tierra para construir vivienda. Aprovecharon las campañas de alfabetización y planificación familiar, y hasta la mujer adolescente se incorporó en nuevas formas de trabajo estacional, cosechando fruta.

Este primer argumento es una tarea de rescate; una de las más antiguas e importantes de la tradición de la historia de género: recuperar la presencia de la mujer, hacerla visible en historias donde tradicionalmente no se ve, o donde se la plantea como "excluida". Yo digo que la mujer no está excluida, sino que está incorporada de una manera desigual y subordinada al hombre. Este es el segundo argumento: planteo que, como parte del proyecto de modernización, el Estado chileno promovía un modelo de familia campesina en el cual los hombres eran buenos proveedores y productores para la nación, y las mujeres eran hábiles y modernas amas de casa. Hace tiempo este modelo fue hegemónico en el Chile urbano, tanto para la clase trabajadora como para la clase media, pero con la reforma agraria se lo extiende al campo, a las campesinas 
y los campesinos. Esta versión del patriarcado modernizado fue muy popular con mujeres campesinas, sobre todo porque prometía elevar la capacidad del hombre para sostener la familia y subrayó la idea de responsabilidad masculina ante las mujeres y los niños. Además, promovía un modelo de relación conyugal complementaria en la que el hombre debe entregar el salario a su mujer y apreciar su labor doméstica y cívica, incluso consultarla sobre la frecuencia del sexo y el número de hijos deseado. Este modelo no imaginaba a la mujer sometida al hombre, sino lo contrario: hombres y mujeres como socios del progreso.

Sin embargo, este modelo hizo a la mujer más dependiente del hombre y claramente privilegió al hombre como actor principal en un proyecto nacional. No es casualidad que el lema de la reforma agraria era "la tierra para el que la trabaja" o que se hablaba de "convertir al humilde campesino en su propio patrón" y de hacerse "un verdadero hombre". La reforma agraria fue, en gran parte, un proyecto para construir una nueva masculinidad campesina. Una masculinidad más independiente, menos humillada, más moderna, hasta militante. Si el hombre debía más respeto y cooperación a su mujer, la reforma agraria afirmó el poder masculino como la piedra angular de la nueva ciudadanía campesina.

El tercer argumento que formulo es que el conflicto de clase de la reforma agraria también involucraba conflictos de género y sexualidad. Examino un aumento de la violencia doméstica contra las mujeres y el abandono del hogar por parte de niñas adolescentes, en relación con un aumento de las oportunidades sexuales para hombres con otras mujeres que conocieron durante sus actividades sindicalistas y viajes de solidaridad con otras comunidades campesinas. Propongo que este conflicto fue integral a la lucha por la tierra, que la pelea conyugal resulta del esfuerzo de la mujer para defender el modelo de familia prometido por la reforma agraria (que incluía fidelidad/responsabilidad masculina), frente a la resistencia de muchos hombres a estas obligaciones, y la creciente tensión entre el ideal del hombre proveedor y el ideal del hombre militante/combatiente en la lucha de clase.

Cuando la reforma agraria se volvió incendiaria durante la Unidad Popular, estos ideales de género fueron sometidos a una extraordinaria presión. Los hombres pasaban mucho más tiempo en reuniones, huelgas y tomas. Al final, el rol masculino del compañero militante se hizo mucho más urgente que el de "jefe de hogar responsable". Las mujeres se sentían cada vez más "solas", sentían que sus familias estaban "abandonadas". El hombre la había traicionado. (Aquí planteo que el conflicto de género se articulaba alrededor de la sexualidad: deseos, actos y significados del cuerpo. Conceptualmente, esto está relacionado con el trabajo de Pateman sobre el sexo y la sexualidad como fundamentales al contracto social y las distinciones de género.)

Metodológicamente, trabajo mucho con historias orales, las que tomo como narrativas sociales, memorias colectivas, valiosas menos por relevar "hechos verdaderos" que por destacar significados de género como discursos del poder. Me impresionó mucho la enorme diferencia entre la memoria de la reforma agraria de los hombres y la de las mujeres. Los hombres, a menudo, la recuerdan como una época tremendamente excitante en la cual viajaron a otras partes del país por primera vez, conocieron nuevos compañeros (y compañeras), y se sentían tomados en serio por los partidos políticos, el Estado y hasta por los patrones; el orgullo de poder entregar zapatos a los niños y una máquina de coser a su mujer; en fin, una narrativa heroica que domina otras memorias de conflicto amargo entre campesinos de distintos colores políticos. Por el contrario, las mujeres (a pesar de su color político) recuerdan la reforma agraria como tiempos de violentas peleas familiares, largos períodos de soledad, preocupación por las hijas y traición sexual de los hombres. 
Digo que este conflicto refleja las formas en las que el modelo de familia campesina moderna hizo a la mujer mucho más vulnerable ante el proceso y la crisis política que la reforma agraria generó, a pesar de lo que fue atractivo del modelo. La participación de los hombres en sindicatos y Centros de Reforma Agraria los capacitó para responder al conflicto social a través de canales institucionales y políticos. Por el contrario, las mujeres estaban organizadas alrededor de identidades de "amas de casa" que las hacían más dispuestas a responder al conflicto social en términos de roles dentro de la familia: roles en los que las obligaciones de los hombres hacia ellas eran más decisivas que nunca.

Quiero saltar al otro libro: Se compraron el modelo: consumo, uva y la dinámica transnacional. Estados Unidos-Chile durante la Guerra Fría (2016). Es un tipo de secuela del primer libro, que me llevó sin embargo por nuevos caminos. El proyecto refleja mi interés en la historia global que nos permite repensar las fronteras de los estudios del área, producidos por la Guerra Fría, especialmente la relación Norte-Sur/EE.UU.-América Latina. También refleja mi interés en cruzar las metodologías y ópticas de los estudios latinoamericanos con las de los estudios culturales estadounidenses (American studies). Así, este libro es intencionalmente interdisciplinario, producto de una larga colaboración con colegas en otras disciplinas (especialmente literatura y antropología) y colegas trabajando en estudios de globalización y en historia global. El giro transnacional está dando vuelta en todas partes, por todas las disciplinas, pero como feminista me llama mucho la atención la ausencia del género como un factor analítico del poder dentro de las nuevas narrativas del campo global o transnacional (Tomás Moulian; Néstor García Canclini; Saskia Sassen). Así, una tarea principal de este libro es hacer del "género" un punto de mira central en una historia transhemisférica: Sur-Norte.

El libro examina la relación entre el apetito norteamericano por la "comida fresca" que emergía con fuerza en los ochenta y el llamado "milagro económico" de Pinochet que terminó la reforma agraria y lanzó un "boom" en la exportación de fruta fresca, una agroindustria con una fuerza laboral cincuenta por ciento femenina: las llamadas "trabajadoras temporeras". Por un lado, este es un cuento antiguo: la abundancia del Norte se funda en relaciones autoritarias del Sur. Estados Unidos consume lo que América Latina produce. Pero yo planteo dos preguntas que pretenden trastornar tal modelo. Primero, pregunto: “¿cuál fue el rol de los chilenos en promover la uva dentro de los EE.UU.?". Los norteamericanos no comen más uva simplemente porque hay más uva. Hay que "abrir el apetito" o "crear el gusto". Incluso hay que construir la idea de que "la comida fresca" es realmente "fresca" y "saludable", y que "lo fresco es bueno para uno". En la década de los sesenta, los norteamericanos preferían la comida en lata y congelada como símbolo de la modernidad. Los empresarios chilenos jugaron un rol importante en cambiar esta idea, en elaborar un nuevo gusto. Junto con los empresarios californianos, los chilenos lanzaron agresivas campañas de marketing dirigidas a la mujer estadounidense. Se apropiaban de mensajes feministas para vender uva como "comida conveniente y sexy", "baja en calorías", "saludable", perfecta para la new woman que había vuelto al trabajo y que era dueña de su tiempo y de su cuerpo. En esta parte del libro propongo la necesidad de "invertir la mirada" Norte-Sur hacia una mirada Sur-Norte. Por largo tiempo, hemos trabajado el tema del impacto de los EE.UU. sobre/dentro de América Latina. En este libro, yo trazo el impacto de América Latina sobre/dentro de los Estados Unidos. Ver "la historia chilena" durante la Guerra Fría como algo que siempre se está desarrollando también dentro de las fronteras de los EE. UU. Y ver la historia norteamericana (los cambios sociales y culturales dentro de sus fronteras) como algo hecho a través de la presencia de actores chilenos. Además, es importante cómo Chile se construye a sí mismo en relación a EE. UU., América Latina y el mundo. 
Por ejemplo, mientras los empresarios californianos favorecían el mensaje de que la uva era un "regalo de la Madre Naturaleza", puro y libre de lo artificial, los chilenos enfatizaron que la uva chilena era "fresca y saludable" porque la fruticultura chilena era una industria ultramoderna que utilizaba la tecnología más avanzada. Si los chilenos tocaron el tema de "la naturaleza" fue para destacar cómo la naturaleza separó a Chile del resto de América Latina para mantener la uva "higiénica" y proteger a Chile de los contagios tropicales de sus vecinos. En el marketing chileno, el cuerpo femenino aparece menos como la mujer sexy/exótica ofreciendo su producto/cuerpo al consumidor (como se vendía la fruta brasileña y mexicana); la uva chilena se vendía con la imagen de la trabajadora moderna, el cuerpo de la mujer en uniforme envolviendo la uva en su malla de plástico. La uva chilena es "fresca" y buena para el cuerpo de la mujer norteamericana porque la ciencia y la industria chilena la hacen así. (Por otro lado, propongo que este fue un modo de producir la imagen de Chile como un país moderno, blanco, excepcional, menos latinoamericano y más californiano).

La segunda pregunta que hago es: ¿qué significa que los y las trabajadoras chilenas de uva también se vuelvan consumidores de nuevos productos de circulación internacional? En este libro, la consumidora principal no es la mujer norteamericana comiendo uva, sino la temporera chilena, comprando bienes en las ferias y mini-malls rurales. Las políticas neoliberales de Pinochet aumentaron enormemente la disponibilidad (incluso para gente muy pobre) de bienes importados: blue jeans, zapatillas, cosméticos. También lavarropas, televisores y heladeras (que se compraron de segunda mano). Me interesa cómo este nuevo consumo, junto con la reorganización laboral en el campo, permitieron una mayor autoridad de la mujer rural dentro de la familia y un mayor poder de negociación con el hombre. Estoy interesada también en el hecho de que las luchas sobre el consumo -el derecho a comprar cosas, las frustraciones sobre la inhabilidad de comprar suficientes cosas- llegan algunas veces a ser lugares para desafiar el régimen militar.

Estudios del neoliberalismo destacan el consumo como "el malo", "el cuco": sinónimo de individualismo, fin de la ciudadanía, una falsa consciencia que derrota la solidaridad de clase. En el caso de Chile, se ha visto a "la mujer chilena" como un ser especialmente vinculado con la seducción del consumo y la política reaccionaria. Aún vivimos con el fantasma de las famosas marchas de las ollas contra Allende, en las cuales las mujeres suplicaron a los militares "ponerse los pantalones y salvar al país del marxismo"; acabar con las colas para comprar pan. Tal cuento era repetido constantemente por Pinochet durante su régimen, llegando a ser la "historia oficial" de la Unidad Popular y haciendo muy difícil ver la relación entre "la mujer" y "el consumo" más allá de la complicidad contra la democracia.

Mi libro desafía la idea de que el consumo bajo el neoliberalismo es necesariamente siempre reaccionario. "El consumo", como tal, no es algo ni "bueno" ni "malo" en sí mismo. En el sentido analítico, "el consumo" es una relación social entre las personas y las cosas, cosas hechas por personas y permeadas con significados elaborados por las personas. Como ha señalado el antropólogo Arjun Appadurai (1986), es mejor ver "el consumo" como "un terreno de lucha", "un campo de negociación del poder". Quién tiene el poder y el derecho de comprarse qué cosas es algo que se pelea, algo que se negocia dentro de la familia y la sociedad más plena. Siguiendo a Victoria DeGrazia y su colección, The Sex of Things (1993), planteo que, para las temporeras de la fruta chilena, el consumo constituía una política cotidiana de la distribución del poder entre mujeres y hombres, padres e hijos: un terreno de lucha marcado por el género tanto como por la generación. Para muchas mujeres, el consumo de los años ochenta elevó su poder dentro de la familia, especialmente en las negociaciones con los hombres. A veces, fue precisamente a través del consumo que la mujer temporera se incorporó al movimiento para la democracia. Subrayo que este ocurre bajo circunstancias muy 
difíciles: extrema pobreza, represión salvaje del movimiento sindical, salarios que valían la mitad que en los años 1968-1973.

Déjenme elaborar. En las zonas frutícolas, la familia campesina empieza a depender de las ganancias monetarias tanto de mujeres como de hombres. Esto marcó un gran cambio respecto del tiempo de la hacienda cuando se pagaba libertad por trabajo familiar al hombre, y aún más grande respecto de la reforma agraria y su promoción de hombres proveedores. La dictadura acabó con el trabajo permanente y los hombres perdieron la tierra y el control sobre las finanzas familiares. Las temporeras (casadas, solteras y adolescentes) controlan sus propios salarios y deciden cómo gastarlos: equiparon la casa con plancha eléctrica, radio-pasacasetes, un lavarropas o un televisor, comprado de segunda mano en las ferias o con crédito. $Y$, a veces, una prenda para uso personal.

La presencia de bienes importados en el campo no fue una novedad de Pinochet. Durante la reforma agraria el Estado distribuía radios, máquinas de coser y cocinas a gas como parte del proyecto de modernizar la familia campesina. Pero en los sesenta, eran los hombres los que agenciaban el acceso de la familia a los bienes de consumo dado que la mayoría de esos bienes se distribuían a través de los sindicatos y asentamientos cuyos miembros fueron casi todos masculinos. Los primeros televisores disponibles para campesinos fueron los de los Centros de Reforma Agraria bajo Allende. Con la dictadura y el derrocamiento del movimiento sindical, el Estado deja de ser la arena principal del acceso al consumo y las mujeres dejan de depender de los lazos políticos del hombre para conseguir un electrodoméstico.

La mujer temporera fue situada más directamente en el centro del modo en que las familias rurales tenían acceso a los nuevos bienes. Los salarios de los hombres generalmente se gastaban en las compras cotidianas de alimentos, el arriendo, la luz, el agua. Los salarios de las mujeres, por el contrario, se invertian más en bienes durables: muebles y electrodomésticos. Artículos que representaban marcas más duraderas de las contribuciones de las mujeres al hogar. También bienes como televisores o radios que podían ser empeñados (vendidos) en los meses de invierno, cuando la plata era escasa. Así, la mujer fue asociada tanto al sistema de ahorro familiar como a la adquisición de bienes.

Fue precisamente la dramática reorganización de la producción agraria que hizo del consumo un terreno clave para socavar el patriarcado familiar. Y esto fue sin duda contrario a los propios ideales del gobierno militar. Pinochet presentó a la mujer chilena como una madre abnegada y apolítica, y al hombre como un soldado y proveedor, claramente jefe de familia. Pero, en la zona frutícola, una de las narrativas más repetidas que encontré en las historias orales fue la insistencia en que ganarplata les daba derecho de controlar su destino. La mujer defendía su derecho a comprar no por invocar "el hogar como una esfera femenina", sino por reclamar el acto más masculino de ser proveedor. Esto significa que la mujer aceptó la lógica neoliberal de la gestión personal a través de transacciones de mercado. Pero también invocó un énfasis más antiguo de la organización sindical y la reforma agraria sobre el derecho del trabajador a los frutos de su trabajo.

La fruticultura implicó grandes cambios en la masculinidad rural: por una parte, una caída de aquel breve momento de la reforma agraria para hacer del hombre campesino "su propio patrón". Pero también una caída de las posiciones de los hombres como "patriarcas marginales" en las haciendas, en donde las vidas de las mujeres dependían directamente de los derechos y deberes de los inquilinos (peones con derechos a la tierra). No obstante, hay bastante evidencia de que en los años setenta y ochenta muchos hombres apreciaban el trabajo de las mujeres temporeras, y hay 
algún reajuste en el trabajo doméstico. El trabajo de las mujeres en los packings tenía lugar por la noche (mientras los hombres cosechaban la fruta durante el día). Esto dejaba a muchos hombres a cargo de los niños y de la preparación básica de la comida durante la ausencia nocturna de la mujer.

Los cambios en la autoridad de género fueron fuertemente cuestionados, a veces dolorosamente. En las historias orales, tanto las mujeres como los hombres se refieren al aumento de la violencia doméstica y al incremento del abandono de las mujeres por los hombres: narrativas que estaban completamente entrelazadas con narrativas que defendían el control de las mujeres sobre los salarios. El aspecto más interesante para mí son los cambios en las razones del por qué el hombre recurría a la violencia. En los casos judiciales de la reforma agraria en los sesenta, las razones principales fueron:

1. Que la mujer descuidó su tarea doméstica.

2. Que la mujer tuvo objeciones a las aventuras sexuales del hombre con otras mujeres. En cambio, bajo Pinochet, la violencia doméstica se centraba más en peleas sobre el dinero, la queja del hombre acerca de que la mujer compraba cosas sin permiso, y la queja de la mujer de que el hombre no ganaba lo suficiente.

3. También hay más casos en que el hombre acusa a la mujer de tener aventuras con hombres que ha conocido en el trabajo.

Además, había ansiedad por la creciente intimidad entre mujeres. Muchos hombres (y mujeres) se burlaban de la mujer temporera por ser una machona o muy hombre. Los maridos acusaban a las esposas de descuidar a las familias a favor de las compañeras de trabajo. Se les advertía sobre supervisoras (mujeres) que supuestamente solicitaban favores sexuales en los packings. Aunque las acusaciones de que las mujeres tenían aventuras con otras mujeres eran relativamente escasas, la ampliación del mundo homo-social femenino sí se percibió como una amenaza. El consumo fue clave para las nuevas formas de comunidad femenina. Dentro de los packings, las mujeres compartían dulces y cigarrillos, jugaban a la amiga secreta, compraban regalos de prendas plásticas para el pelo y esmalte de uñas como pequeños símbolos de compromiso mutuo. Se vendían cosas entre ellas. La circulación de catálogos de cosméticos de Avon se volvió enorme. Las mujeres recibieron premios de la compañía norteamericana para llevar a sus compañeras de trabajo a "fiestas" donde se mostraban y vendían cremas, champú y ropa interior. Los regalos entre las temporeras se inscribían a menudo en un lenguaje de relación heterosexual en vez de en los antiguos discursos de ser una "buena vecina". La mujer que "invitaba" a otra mujer a una Coca-Cola o le regalaban un lápiz labial, era agradecida (en burla) por ser un buen marido. Las trabajadoras de la misma cadena de embalaje se referían mutuamente como "pololas". Lo que esos intercambios nos muestran no es tanto una nueva cultura lesbiana, sino cómo las prácticas del consumo dieron derecho a tipos de autoridad sexual que antes estaban reservados al hombre: el poder de "invitar" y "regalar" y, a cambio, esperar lealtad y cariño.

A veces, el consumo llegó a ser un evidente terreno politizado al cuestionar el régimen militar. De hecho, los únicos desafíos públicos a la dictadura que yo encontré eran movilizaciones en torno a problemas del consumo. No tengo tiempo para profundizar, pero, por ejemplo: la proliferación de las ollas comunes como una crítica a la promesa de abundancia del libre mercado. O la participación de las temporeras en las comunidades eclesiales de base organizadas por la Iglesia que muchas veces servían para discutir la pobreza y la violencia doméstica como efectos de la falta de democracia. Por último, las mujeres y el consumo son cruciales al renacimiento del movimiento sindical. En la década de 1980, la mitad de los miembros de nuevos sindicatos frutícolas creados con el apoyo de la Iglesia y de 
la izquierda clandestina son mujeres, incluso en posiciones directivas. Durante el Plebiscito Nacional, las temporeras Ilevan la Campaña del "No" contra Pinochet. Y la zona frutícola será casi la única zona rural donde Pinochet pierda. (El "Sí" ganó en todo el campo, menos en las zonas de exportación forestal y frutal.) Pinochet pierde precisamente en las regiones más famosas por el "milagro económico", y pierde porque una mayoría de las mujeres temporeras vota en su contra.

Para cerrar, quiero asegurarles que no planteo que la dictadura de Pinochet fue "buena para la mujer campesina". No podemos confundir la agencia de mujeres y hombres en negociar su realidad con el proyecto militar de reforzar la familia patriarcal y limpiar la sociedad chilena de la política. Hay que insistir en la "dialéctica feminista”. (Nunca se dice que la formación del movimiento obrero masculino refleja lo emancipatorio de la explotación capitalista). Ver el "patriarcado" como una constelación de modos de poder constantemente negociado nos ayuda a evitar dicotomías falsas y preguntas simples sobre las mujeres que jamás haríamos sobre los hombres. Nos permite distinguir entre proyectos estatales, estructuras y condiciones de familia y de trabajo, y el proceso de negociar el poder dentro de ellas. Incluso abrir nuevos espacios y relaciones de poder para investigar, como la política de género en el consumo y el género en la historia transnacional. Nos permite tomar nuevos terrenos. Así los dejo, con una metáfora de reforma agraria...

Isabella Cosse: Muchas gracias Heidi. Fue una conferencia magnífica. Queremos agradecerte especialmente por aceptar dictarla sobre el tema que te propusimos al invitarte. Justamente, queríamos poder pensar y discutir sobre el patriarcado en función de tus propias investigaciones. ¿Te parece si abrimos una ronda de preguntas?

Heidi Tinsman: Sí. Ojalá que me hayan entendido el idioma.

Isabella Cosse: Se entendió perfectamente. Quiero preguntarte por tu trabajo como historiadora en dos proyectos que están muy conectados pero son distintos. Me interesaba saber cómo había sido la construcción de tu interpretación, de tu proyecto en cada uno de los libros. Pensaba que la reforma agraria era una temática de indudable importancia mientras que ocuparse de la uva debió ser diferente, trabajar sobre un tema cuya significación política y social no resulta igualmente evidente. Creo que hay dos trabajos muy distintos y que implican dos legitimaciones distintas, distintos modos de construir en términos de su significación y quería preguntarte por esas diferencias históricas. Además, en relación con el segundo libro quería preguntarte qué repercusiones ha tenido tanto en Chile como en EE.UU.

Heidi Tinsman: La relación entre los dos proyectos. Yo llegué a Chile en el noventa y uno para trabajar con los temporeros. Llegué porque iba a abandonar la carrera académica. Llevaba varios años en el programa de posgrado. Pensaba que era muy largo, que no valía la pena, que el mundo no necesitaba otra historiadora. Llegué a Chile becada por la escuela de derecho a trabajar voluntariamente con un sindicato de mujeres temporeras. No llegué para hacer mi investigación doctoral, yo estaba pensando originalmente que iba a trabajar un proyecto sobre trabajo doméstico en Brasil durante Vargas. Algo muy bonito. Mi directora de tesis fue Emilia Viotti Da Costa, una de las grandes historiadoras brasileñas exiliada en los EE.UU. Pero no fue por culpa de la historiografía brasilera que me desilusioné. Cuando estaba en Chile descubrí la reforma agraria, ese proceso tan radical, y retomé el doctorado y decidí hacer la tesis sobre los [años] cincuenta, comenzando con la mujer en la hacienda, la reforma agraria y Pinochet. Ver el proceso de cambio. Porque había muchas mujeres feministas chilenas haciendo trabajos excelentes, como Ximena Aranda, Ximena Valdez, Sonia Montecinos. Era un momento clave para hacer trabajos sobre historia agraria. Cuando me senté a escribir la tesis decidí que no solo tenía mucho material sobre reforma agraria, sino que el tema se merecía su 
propia historia social porque era un proceso de movilización y cambio social muy profundo. Pero esta historia la traté como una historia nacional, un relato sobre la democracia radical y el proyecto de desarrollo nacional. Cuando volví a tomar el tema de la fruticultura en 2005 , ya tenía cajas y cajas, y entrevistas con temporeras de la fruta que hice a comienzo de los noventa, y volví varias veces durante los siguientes cuatro años a Chile a hacer más investigación con más preguntas sobre el consumo. Pero ahora vi el tema de la fruticultura con una mirada más transnacional, no solamente un relato sobre Chile como nación. Estaba interesada en la dinámica EE.UU.-Chile, me interesaba la historia de las Américas, repensar antiguos modelos de estudios latinoamericanos. Y no escribí una historia nacional. Aquí está la mujer y esta es una historia de la mujer y su proceso de proletarización, podría haber hecho eso, pero fue por otro lado. Me apenó darme cuenta de que cuando había estado haciendo la investigación sobre la reforma agraria podría haber hecho más preguntas sobre el consumo, porque el tema ya estaba ahí.

Dora Barrancos: Heidi es parte de esa generación intermedia de historiadoras norteamericanas capaces de renovar sus propias concepciones. Creo que, sintéticamente, Heidi fue una insurgente respecto de algunas cuestiones pero hay dos en las que todo el mundo va a estar de acuerdo. La primera insurgencia fue visibilizar a las mujeres en el área rural, en donde parecía que estaban tan bien exoneradas, a propósito del gran proceso de la reforma agraria chilena. Heidi nos revolucionó esas concepciones y nos entregó la tierra para el que la trabaja, un texto memorable. La segunda insurgencia fue rebatir que el consumo es antirrevolucionario de alguna manera. Que el consumismo revela una esfera de satisfacciones que aletargan las condiciones de posibilidad de ciertas subversiones. En ese sentido, me llama un poco la atención que en la orientación de consumos de las mujeres estuvieran un poco más remarcados aquellos consumos que tienen que ver con productos duraderos. La pregunta es: Inés Pérez, una colega de las nuevas generaciones, muy interesante, ha estudiado el consumo en Mar del Plata, y ella ha marcado (y me parece que no solamente ella) una especie de predilección de los varones, autorizantes, para comprarles objetos duraderos domésticos a sus mujeres. Pero las mujeres tenían cierta reticencia a esos objetos duraderos. A pesar de ello los varones decían que eran interesantes y... traían una lavadora. Lo que tú marcas, en cambio, es una orientación hacia los bienes durables de las propias mujeres. Sabemos también que hay una desmentida sobre cierta futibilidad de los consumos femeninos que se van en bienes no duraderos.

Quiero decir, antes que nada, que hoy en Chile hay muchas chilenas que están trabajando la historia del consumo en los cincuenta y en los sesenta. Aquí en Argentina aún más. Es súper importante no ceder. No podemos regalar ese tema a la derecha, el campo del consumo. No se puede hacer eso. Bajo Pinochet hay muchos tipos distintos de patriarcado. Si dentro de la familia hay una renegociación del poder relacionado con el consumo, no quiere decir que estamos hablando de mujeres emancipadas. Ellas jamás narran sus vidas como emancipadas, porque son tan pobres y es tan doloroso cuando la pareja se va; esa no es una narrativa de liberación. Pero, por otro lado, existe este orgullo de poder armar la casa, de seguir luchando. No soy yo la única en subrayar que en los movimientos por la democracia en Chile las mujeres son protagonistas por muchas razones; incluso la represión grande hacia el hombre. Entonces había más posibilidades para que la mujer protagonizara alguno de esos proyectos, con la compra de bienes durables para la casa. Quiero subrayar que eso no es lo mismo que decir que Pinochet fue bueno para la mujer. Sino decir que dentro del proyecto de la dictadura podemos ver a la mujer tomando la lucha y nuevas formas de agencia. Pero hay otros tipos de patriarcado que son mucho más agudos: el control del hombre sobre la mujer dentro del packing (es decir en el área de empaque de la producción), el control brutal del Estado sobre la ciudadanía, que también es una forma patriarcal. Por eso 
subrayo la idea de patriarcados múltiples, no uno, porque eso nos lleva nuevamente a preguntas como "capitalismo-dictadura, ¿es bueno o malo para la mujer?" Esa es una pregunta que jamás haríamos respecto de los hombres.

Andrea Andújar: Sé que no es tu intención, pero cuando leo el libro y lo comparo con el primero, pareciera que el consumo es causal de diversas relaciones sexuales, está estableciendo pautas de comportamiento, proveyendo identidades. Y no es el resultado de, tan solo; es una relación más dinámica pero en algún punto pareciera que el consumo está asumiendo el lugar protagónico. Y me pregunto entonces cómo historizarlo, porque en verdad si yo pienso en términos de relaciones sociales o de demandas de distinta naturaleza, el consumo ha estado presente en buena parte de la conflictividad de los últimos dos siglos. El tema es cómo situarlo o, ¿hasta qué punto da efectivamente lugar a relaciones sociales, a las entidades sociales, a las gestaciones de subjetividades? ¿El consumo podría ser la causa del resto de las relaciones políticas o no? Porque en algún punto pareciera asumir un rol protagónico. Quiero saber si es una interpretación mía o no.

Heidi Tinsman: Yo no veo al consumo como protagonista. Yo veo a las mujeres ya los hombres como protagonistas. Si hay algo, es la pobreza, la extrema pobreza que domina las vidas de los temporeros durante los setenta y los ochenta. Entonces, no se puede elaborar la historia del consumo sin narrar, sin mostrar esta historia de extrema pobreza, que casi la mitad de las familias en las zonas frutícolas tienen jefas de hogar mujeres. Después de la reforma agraria, si una mujer no tenía marido, iba a la ciudad a buscar trabajo como nana, niñera. Eso no es liberación. Yo no trato la extrema pobreza bajo Pinochet como liberación, nunca jamás utilizo la palabra liberación. Pero, como tú dijiste, el consumo ha existido desde tiempos antiguos, siempre estamos consumiendo. Lo que podemos estudiar como intelectuales (o como personas que nos importa la política) son las distintas dinámicas del consumo: el consumo como un "terreno de lucha," el consumo como un modo del poder que ordena las relaciones sociales de las personas a través de la producción, el uso y el significado de las cosas, hechas por las personas. Así, el consumo es parte del proceso social, no una "fuerza" ni "causa" aparte. Podemos hablar de mil formas de consumo, igual que como analizamos distintas formas del capitalismo y de economías no capitalistas. La tarea es reconocer el consumo como una dinámica del poder importante para entender la historia humana. Eso es decir que la historia del consumo, o el tema del consumo dentro de la historia, opera en modos diferentes en distintas épocas históricas. Para mí era muy importante en este segundo proyecto hablar más del consumo durante la reforma agraria. Viendo la reforma agraria desde estas preguntas yo digo: hay muchísimas nuevas formas de consumo durante la reforma agraria y las y los historiadores tienen que retomar este campo. El cuento de que los bienes de circulación se ganan con el neoliberalismo es una historia política de la derecha, no es algo históricamente dado. Pero nosotros como intelectuales tenemos que tener cuidado con repetir esa narrativa. Además, no podemos ignorar que las mujeres, en este caso de la zona frutícola, tenían más agencia, que la que podríamos pensar inicialmente, para manejar la extrema pobreza. Muchas de ellas no tienen marido, no tienen un hombre en la casa. Y eso no es una situación emancipatoria, es porque el hombre se fue a buscar trabajo a otro lado. Pero ellas realmente están tomando las decisiones y si invierten en bienes durables es porque a ellas les importa mostrar que armaron su casa, "aquí mando yo". Hay orgullo en ello y no podemos ignorarlo. Porque eso me va a llevar a una narrativa que dice “¡Oh, qué bueno Pinochet!”. La fruticultura pagaba un salario que valía la mitad de lo que valía en los setenta y ese salario no se va a recuperar hasta fines de los noventa. Muchos de ustedes seguramente estudian zonas urbanas. Hay miles de casos de pobreza extrema donde existen electrodomésticos. La presencia de electrodomésticos no significa la ausencia de pobreza, al contrario. 
Oradora sin identificar: Vos decías que a partir del neoliberalismo el consumo dejó de ser mediado por el Estado. Entonces a mí me quedó rebotando la idea porque normalmente asociamos el concepto de consumo con el mercado...

Heidi Tinsman: Eso es un problema porque hay otras maneras de consumir.

Oradora sin identificar: ...entonces: ¿cómo definiríamos el consumo si se expande y es más amplio que su centro, del mercado, de las lógicas del mercado?

Heidi Tinsman: Depende de qué queremos decir por mercado. Los mercados son antiguos. Desde tiempos antiguos hemos tenido mercados. Pero cuando se utiliza la palabra mercado en relación a narrativas sobre la globalización de fines del siglo XX y principios del XXI, estamos hablando de mercado neoliberal capitalista. Pero esa no es la única forma de mercado. Hay mercados en este momento, a mediados del siglo XX, con el modelo desarrollista, del desarrollo comandado por el Estado, que no es exactamente socialismo, pero en el cual el Estado juega un rol muy importante dentro de los mercados. Pero con Pinochet, el Estado jugó un rol importante en facilitar lo que llamamos libre mercado. Pero dentro de ese proyecto lo que estoy distinguiendo es que tanto en la reforma agraria, el Estado de Frei, el Estado de Allende jugó un rol muy importante en distribuir bienes dentro de distintos mercados para campesinos. Y eso fue sumamente importante para ese modelo de familia moderna que usé en mi primer libro. El consumo es una relación social, eso es. Esto significa que el consumo depende del momento, y de nuestra óptica política, por supuesto. Entonces lo que es consumo durante la Unidad Popular es diferente de lo que es consumo en el ochenta y cinco. Lo que es consumo en el campo es diferente a lo que es consumo de clase media santiagueña. Darte una definición simple de relación social, no es simple. Es nuestra tarea decir cómo está construida esa relación social. Cuáles son las relaciones de poder que la hacen.

Gabriela Mitidieri: A veces hemos dejado afuera la noción de patriarcado por ser aparentemente una noción demasiado política como para ser una categoría académica, y otras veces también el patriarcado, incluso en las luchas feministas, ha sido como esa gran cosa opresiva, inmutable e invencible. ¿Cómo podemos incluirla de un modo que sea útil para pensar adecuadamente los contextos históricos que abordemos? Sobre todo pensando en tu intento tan interesante de pensar el patriarcado en escalas múltiples. Mi pregunta va en esa dirección: de qué manera estás pensando el patriarcado dentro de la historia social.

Lo que intenté aquí en relación al patriarcado es remarcar que desde hace varias décadas muchas feministas están utilizando el concepto de patriarcado como una constelación heterogénea. Muchos modos de poder. Muchos sitios de poder. Hace tiempo que hemos dejado de discutir el patriarcado como un sistema, o una estructura. Y eso es bueno. Pero ¿sabes qué?, hay palabras que a veces, para algunas personas, están contaminadas, que siempre va a invocar sistema. Pero yo creo que vale la pena retomarla. Lo encuentro muy útil pero eso no quiere decir que siempre haya utilizado la palabra patriarcado. Lo que tomé de las chilenas en los noventa era el énfasis del concepto de patriarcado en el Estado, en el sistema político. En los noventa, fines de los ochenta, era urgente hablar de poder, de género, en términos de estructura, sistemas, leyes. Y todavía, créanme, lamentablemente es relevante.

Carla Villalta: Me encantó realmente tu exposición Heidi y pensaba en esto del desplazamiento tan necesario de determinados lugares explicativos comunes, o clichés que pueden ser en parte explicativos pero que a la vez homogeneizan o dejan determinadas facetas invisibilizadas. Y pensaba en dos cosas. En esto del consumo de lo que ya venimos hablando y en la relación Norte-Sur, que te pediría que amplíes, ya que me parecía muy interesante poder mirarla desde otra 
perspectiva y complejizar estas explicaciones tan contextuales y políticas, que tienen una finalidad de denuncia, de intervención en la arena política. Y, por otro lado, en relación con el consumo, recordar un trabajo que para nosotras, las antropólogas, es fundamental, la etnografía clásica de Evans Pritchard sobre los Nuer del Sudán, donde analiza cómo fue la introducción del dinero en esta sociedad primitiva y sin Estado, y lo hace también pensando en cómo el dinero no es tan solo el universal intercambiable, sino que, en una cultura, esos pueblos reapropian, resemantizan, resignifican y crean nuevas categorías de riqueza. Cómo también el dinero influye y genera efectos imprevistos en las relaciones familiares y en las relaciones entre géneros. Me resonaba mucho con tu trabajo.

Heidi Tinsman: Claro, sí. No tenía tiempo en esta charla, pero en el libro trabajo ese tema. Porque en los ochenta había mucha preocupación de la izquierda y de la Iglesia progresista por el consumo. "¡Se está destruyendo la cultura campesina auténtica!”, “¡Están destruyendo a la mujer! La mujer está sentada todo el día frente al televisor”. Créanme, las mujeres estaban en el packing, pero sí sentían mucho orgullo de comprarse un televisor. Pero el significado de tener un electrodoméstico para la temporera, subrayo, era muy diferente a lo que creían los dirigentes de la izquierda clandestina y la Iglesia. Y más aún de lo que creía Pinochet. Algo interesante que pasa es que todos esos electrodomésticos se compran en segunda o tercera mano, muchas veces rehechos. Son televisores que están hechos con un cable de acá, un tubo de acá, un aparato de aquí y encima se coloca una etiqueta que dice "RSA" o "Sony". O sea, la etiqueta de marca internacional era súper interesante para las temporeras, no porque ellas estuvieran inconformes con la dictadura, sino porque era a través de los electrodomésticos supuestamente hechos en EE.UU. (que en realidad no eran hechos en EE.UU. sino en San Felipe, eran rehechos por chilenos; en el sentido de Walter Benjamin es una copia de una copia que circula), era través de las copias de las copias que las temporeras podían participar de lo cosmopolita como campesinas; ellas jamás dejan de auto referirse como campesinas, ellas se definen como campesinas. Una campesina sin acceso a la tierra. Por décadas y décadas, casi siglos, hubo (y hay) campesinos sin acceso a la tierra. Por eso necesitábamos una reforma agraria. No tiene que tener acceso a la tierra para identificarse como campesino. Entonces por eso yo pujo contra el discurso ansioso de la izquierda y de la iglesia progresista que dice que el consumo está destruyendo a la auténtica campesina. Por tener máquinas lavadoras de tercera mano no está destruyendo la cultura campesina, está ahorrando 16 horas de labor para la mujer que tiene que estar en el packing.

Dora Barrancos: La inmoralidad del tener. Hay un discurso que todavía persiste de la inmoralidad del tener, muy típica justamente de las convenciones de izquierda y de los cristianos, y yo solamente voy a dar una referencia. Hace poco escuché a Pepe Mujica, presidente de Uruguay, y su visión es un anatema contra el consumo. Con lo cual nos da una incomodidad terrible, porque todavía hay una afectación de los sentidos de la ética que tienen una contraindicación con respecto al consumo. Pero en realidad, gran parte de las humillaciones humanas se han hecho por no tener. El derecho a tener. Entonces es un oxímoron dentro de la izquierda. Tenemos que resolverlo porque justamente en momentos como este ponen al rojo vivo la brutalidad de la inequidad con el subconsumo. La imposibilidad del consumo. De modo que tenemos que ponernos de acuerdo [risas]. La verdad es que, cuando Isabel Larguía hizo aquel trabajo tan notable, muy bello, mostró que las mujeres que podían consumir compraban artefactos para tener menos tiempos muertos todavía ${ }^{2}$. El artefacto en la casa permitía que luego el tiempo del lavado fuera para zurcir. Y si se compraba algo para esto, se tomaba más tiempo para hacer cortinas. Una idea que efectivamente también es una ética fundada en nuestro género, la idea de no tener tiempos muertos. Por eso me parece extraordinario que estas mujeres hayan conquistado el derecho a tener objetos durables
2. Larguía, I. y Dumoulin, J. (1971). Hacia una ciencia de la liberación de la mujer. La Habana: Casa de las Américas. 
en su casa como una demostración de lo que se puede y de una cierta dignidad en sí, también.

Heidi Tinsman: Y que son trabajadoras. Que su orgullo, que yo vi, era decir "soy trabajadora, no ama de casa. Con mi dinero yo compré eso".

Guadalupe Ballester: Vos nombrabas los trabajos de García Canclini y esta idea del consumidor ciudadano, de la posibilidad de pensar los consumos en términos de la ciudadanía. En el caso de las mujeres en un contexto en el cual el juego político está totalmente bloqueado en una dictadura, incluso en zonas rurales se exacerba más la construcción de una nueva forma de participación social desde el trabajo y el consumo.

Heidi Tinsman: Eso es lo que argumento. El trabajo de Canclini fue muy importante para mí. No estoy diciendo que bajo condiciones de dictadura el neoliberalismo no destruya, sí destruye y destruye espacios cívicos, organizaciones populares y sindicales. Entonces, estoy de acuerdo con García Canclini y estoy diciendo que hay algo más. Yo creo que Canclini también decía que el consumo es algo que se pelea, se negocia.

Guadalupe Ballester: Sumarle el género es algo más interesante. ¿Cómo lo piensas? Heidi Tinsman: Sí. Y no es que todas las mujeres son ángeles. Están participando dentro de lo que es la nueva ciudadanía neoliberal, pero también están desafiándola. Y están utilizando discursos de la reforma agraria y del movimiento sindical, del derecho del trabajador a los frutos de su trabajo. Entonces no es solamente un discurso de ciudadanía neoliberal, también hay otros discursos y sentidos de derechos, el derecho de tener puede ser muy radical. Lo que ahora están trabajando historiadores chilenos con el proyecto de Allende, o con proyectos de la Revolución Cubana, nicaragüense, es que los proyectos izquierdistas que ganan se preocupan por el consumo, saben que hacían una promesa de que los pobres iban a poder tener más cosas. Ni siquiera el Estado de la izquierda, el Estado de Frei estaba preocupado porque los pobres tengan acceso a la tierra, a máquinas. Frei era famoso por distribuir máquinas de coser y radios.

Isabella Cosse: Has señalado en varios momentos que muchas mujeres trabajadoras chilenas son mujeres jefas de hogar y que el hecho de que el marido se haya ido no es una liberación. Recuerdo, también, el modo tan rico de pensar la conexión entre los conflictos de las parejas campesinas (y también de las mujeres y las hijas jóvenes) con la lucha política en el escenario de la reforma agraria. Quería, entonces, preguntarte por tu enfoque sobre esa relación tan estrecha, dinámica, entre lo familiar y lo político. Y si los efectos políticos de esa conexión cambiaron antes y después de la dictadura.

Heidi Tinsman: Es verdad que en los dos proyectos me interesa el lazo entre la política familiar y otras dinámicas políticas: políticas del Estado, de las organizaciones laborales en las haciendas y los packings, las políticas de movimientos sociales. Aquí, sigo elaborando el paradigma marxista-feminista de lo interconectado de la familia y la economía. Insisto en que las relaciones del poder y las negociaciones, luchas, alianzas, acuerdos dentro de la familia son "lo político"-el espacio más cotidiano de lo político/la política- ya sea en la reforma agraria o en la fruticultura bajo la dictadura. Pero, por supuesto, trazo un gran cambio: de la familia patriarcal moderna de la reforma agraria a la familia precaria y muchas veces con jefa de hogar de la dictadura. Y durante la larga transición a la democracia (todavía en camino), hay todavía más cambios: sin duda veinte años de gobierno de centroizquierda han elevado el estándar de vida en el campo, no obstante el modelo neoliberal y la desigualdad persisten; pero a la vez, hay más validación de la mujer como trabajadora, proveedora y dirigente social que refleja la historia del liderazgo de la mujer dentro de los movimientos sociales durante la dictadura. (Obviamente, sigue el 
conflicto de género y generación, y Chile no es pospatriarcado ni poshistoria. Pero la democracia importa y también el legado del protagonismo femenino dentro de los movimientos por la democracia).

Cristiana Schettini: Mi pregunta se refiere a la articulación de una multiplicidad de escalas en tu trabajo. Me llama la atención cómo la dimensión transnacional de la pregunta sobre los múltiples sentidos sociales, económicos y políticos de la uva chilena en Estados Unidos, permitió iluminar procesos fuertemente conectados, y a la vez cruzados por tensiones, conflictos y antagonismos. Por eso, me gustaría que nos contaras cómo se fueron definiendo la multiplicidad de escalas en el proceso de investigación. Además, quisiera saber en qué medida la experiencia de esta investigación incidió en tu nuevo proyecto que parece radicalizar aún más la articulación de escalas y sus consecuencias analíticas, al abordar la movilidad de trabajadores chinos por diferentes partes del continente americano.

Heidi Tinsman: Siempre estamos trabajando con una multiplicidad de escalas, o la posibilidad de ellas. Aún en la historia nacional o local, la historia de una ciudad. Hay que decidir con intención el enfoque y qué partes de la historia te importan más. No estoy totalmente segura acerca de si el problema de escala es más complicado en la historia transnacional, pero es tal vez aún más crucial decidir el "framing". Existen límites al alcance razonable que un buen libro puede tener e inmensos impedimentos prácticos para realizar investigaciones en diversos idiomas. Creo que el desafío fundamental de un proyecto transnacional es yuxtaponer objetos de estudio pertenecientes a diferentes campos o tradiciones para obtener nuevos ángulos de entendimiento. Mi libro sobre la uva y el consumo se enfoca intencionalmente en la relación entre Chile y Estados Unidos (más que en otros lugares donde iba la uva chilena -a Japón y Canadá, por ejemplo- para poner de relieve la manera en que los estudios latinoamericanos (Latin American studies) y los estudios norteamericanos de Estados Unidos (U.S. American studies) han generado mutuamente una gama de presunciones sobre el consumo y la producción, sobre el imperialismo y la dependencia, sobre el norte y el sur. La mujer trabajadora chilena es la principal consumidora de la que trato, debido a que, en general, se supone que los/las trabajadores/as del "tercer mundo" están fuera de la cultura mundial del consumidor, o bien que ella los explota. Al consumidor estadounidense se lo presenta más como el blanco de campañas publicitarias, y de los boicots en los que los chilenos tuvieron una participación, que en términos de sus propias transformaciones y luchas políticas (que han sido estudiadas con más detalle en otros trabajos). No se trata de que otras historias sean menos importantes ni que su contribución sea menor, sino que las decisiones que se han tomado forman parte de la metodología del libro.

Mirando hacia el futuro, en el nuevo proyecto sobre trabajadores chinos y los lazos China-América Latina, también tendré que poner mucha atención e intención en la cuestión del framing y las escalas. No tengo tiempo de elaborar esto aquí, pero te prometo que este futuro libro transhemisférico va a ser más corto en cantidad de páginas que mi segundo libro transamericano sobre el consumo y la uva, que a su vez fue más corto que el primer libro sobre la historia nacional de la reforma agraria chilena. 


\section{Q Referencias bibliográficas}

》Appadurai, A. (1986). The Social Life of Things: Commodities in Cultural Expression. Cambridge, Reino Unido: Cambridge University Press.

"Aranda, X. (1981). Mujer, familia, y sociedad rural. El Valle de Putaendo. Santiago de Chile, Chile: Ford Foundation.

»DeGrazia, V. y Furlough, E. (1993). The Sex of Things: Gender and Consumption in Historical Perspective. Berkeley, Estados Unidos: University of California Press.

"Gaviola, E., Jiles Moreno, X., Lopresti Martínez, L. y Rojas Mira, C. (1986). Queremos votar en las próximas elecciones: historia del movimiento femenino chileno, 1913-1952. Santiago de Chile, Chile: CEM.

"Kirkwood, J. (1986). Ser política en Chile: Las feministas y los partidos. Santiago de Chile, Chile: FLACSO.

»Larguía, I. y Dumoulin, J. (1971). Hacia una ciencia de la liberación de la mujer. La Habana, República de Cuba: Casa de las Américas.

»Pateman, C. (1995). El contrato sexual. Barcelona, España: Anthropos.

"Scott, J. W. (2012). Gender and the Politics of History. New York, Estados Unidos: Columbia University Press. Publicado en castellano como Scott, J. W. (2012) Género e historia. México, México: Fondo de Cultura Económica.

»Tinsman, H. (2009). La tierra para el que la trabaja. Género, sexualidad y movimientos campesinos en la Reforma Agraria chilena. Santiago de Chile, Chile: LOM Ediciones.

»Tinsman, H. (2016). Se compraron el modelo. Consumo, uva y la dinámica transnacional: Estados Unidos y Chile durante la Guerra Fría. Santiago de Chile, Chile: Ediciones Universidad Alberto Hurtado.

"Valdés, X. (1992). Mujer, trabajo, y medio ambiente: los nudos de la modernización agraria. Santiago de Chile, Chile: CEM.

"Valdés, T. (1992). Ser mujer en sectores populares urbanos. Santiago de Chile, Chile: FLACSO. 